\title{
New Controller Design for PMSG Based Wind Generator with LCL-Filter Considered
}

\author{
Marwan Rosyadi, S. M. Muyeen, Rion Takahashi, Junji Tamura
}

\begin{abstract}
In this paper design and analysis of the grid side converter controller for Permanent Magnet Synchronous Generator (PMSG) based variable speed wind generator connected to a grid through LCL filter are presented. Since utilization of the LCL filter in output of the converter can lead to stability problem due to resonance at high frequency, determination of the controller parameters should be carefully designed. In this study, a simple dynamic model of the LCL filter is developed in order to analyze the performance of the control system easily. By using the bode diagram and step response of the system, the combination of gain controller and damping resistance parameters can be selected. The proposed method has been implemented on the grid side controller design for 2.5 MW PMSG based variable speed wind generator. The simulation results show that the proposed method is very useful and good response performance of the control system can be achieved.
\end{abstract}

Index Terms --Variable speed wind turbine, PMSG, voltage source converter, LCL filter, passive damping resistance

\section{INTRODUCTION}

$\mathrm{D}$ UE to the problem of global warming, utilization of distributed generation system which is connected with distribution grid system has been interested and received considerable attention nowadays. The distributed generation can be located close to load consumers. It can have some merits: increasing the available power, improving the overall system reliability, lower costs, reducing emissions, and expanding their energy options [1]. The wind power is one of the distributed resources. Connecting wind turbine generator to distribution grid system leads stability problem. Therefore, it is very important to analyze a suitable control design for wind generators connected to the grid.

Over recent years megawatt class of Variable Speed Wind Turbines with Permanent Magnet Synchronous Generator (VSWT-PMSG) have been manufactured and become the most popular type of wind turbine generator. The VSWT-PMSG system is designed to achieve maximum aerodynamic efficiency, increase energy capture, and reduce mechanical stress on the wind turbine [2]. The generator can be directly driven by a wind turbine without gear transmission. In addition, the permanent magnet machines have large air gaps which reduce flux linkage although with multi magnetic poles [3], [4]. However, this type of wind generator has more complicated controller system compared with other types. Therefore, the analysis method to design controller system of the generator still needs to be improved.

The VSWT-PMSG is, in general, connected to the utility power system through the voltage source power converters. The converter permits very flexible control of active and

Marwan Rosyadi, R. Takahashi, J. Tamura are with the Electrical and Electronic Engineering Department, Kitami Institute of Technology, Kitami 090-8507, Japan (e-mail: marwanrosyadi@yahoo.co.id).

S. M. Muyeen is with the Department of Electrical Engineering, the Petroleum Institute, Abu Dhabi, UAE. reactive power flows to the grid system. The full power converter totally decouples the PMSG from the grid, and hence grid disturbances have no direct impact on the generator. However, the converter is operated at high switching frequencies between $2-15 \mathrm{kHz}$ resulting high order harmonics which can disturb devices on the grid and generate power losses [5], [6].

In order to reduce harmonic currents injected to the grid, LCL filter is an attractive solution because of its many potential advantages such as higher harmonic attenuation and smaller inductances compared with L filter [7]. However, resonance at high frequency caused by the filter can lead stability problem. Determination of controller parameters should be considered in design application. To avoid the resonance problem, a passive damping resistance should be adopted in the LCL filter although this method can reduce the filter effectiveness and increase losses [6]. Selection of a damping resistance value should also be taken into account in the controller design of VSC as well as the filter effectiveness and its losses.

In this paper design and analysis of the controller for 2.5 MW class of the VSWT-PMSG connected to distribution network are presented. This study is concerned with the investigation of the stability performance of current controlled grid side converter connected to the grid through LCL filter. The controller is designed based on the synchronous d-q reference frame. A simple dynamic model for LCL filter including damping resistance is proposed as plant system in which the configuration of the filter can be accurately represented. Analytical expressions and plots are given to show the system stability performance. Simulation results show that the controller system is very effective to control power delivered to the grid with small total harmonics distortion.

\section{VSWT-PMSG MODEL SYSTEM}

The block diagram of control system for VSWT-PMSG considered in this paper is shown in Fig. 1. The VSWTPMSG consists of the following components: a direct drive PMSG, two levels back to back converters composed of stator side converter (SSC) and grid side converter (GSC), a DC-link circuit with a capacitor $\left(C_{d c}\right)$, stator side controller, and grid side controller.

The SSC is connected to the stator of PMSG, and it converts the three phase AC voltage generated by PMSG to $\mathrm{DC}$ voltage. The three phase voltage and current sensors are attached on the stator terminal of PMSG. The rotor speed of PMSG is measured from the rotor of wind turbine.

The GSC is connected to the grid system through LCL filter and a step up transformer. The grid current and the grid voltage sensors are attached on converter side and grid side of the LCL filter, respectively. The DC voltage $\left(V_{d c}\right)$ across the DC capacitor is detected. The voltage reference of grid side voltage source converter for modulation is controlled by using the grid side controller. 


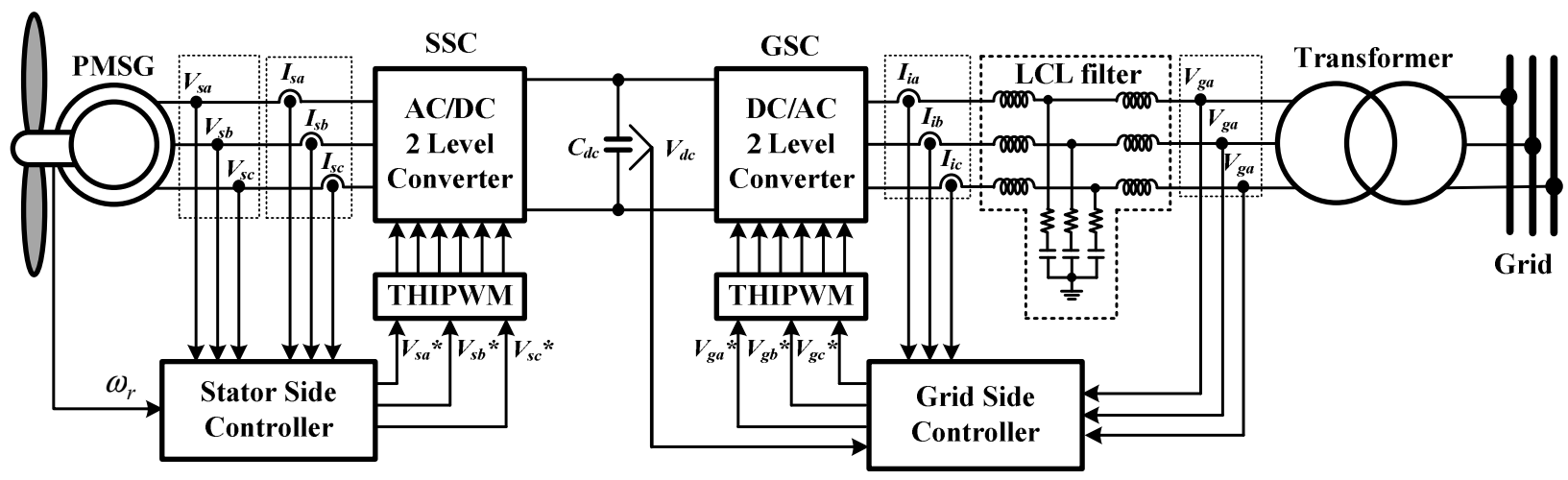

Fig. 1. Model and control system of PMSG based variable speed wind turbine

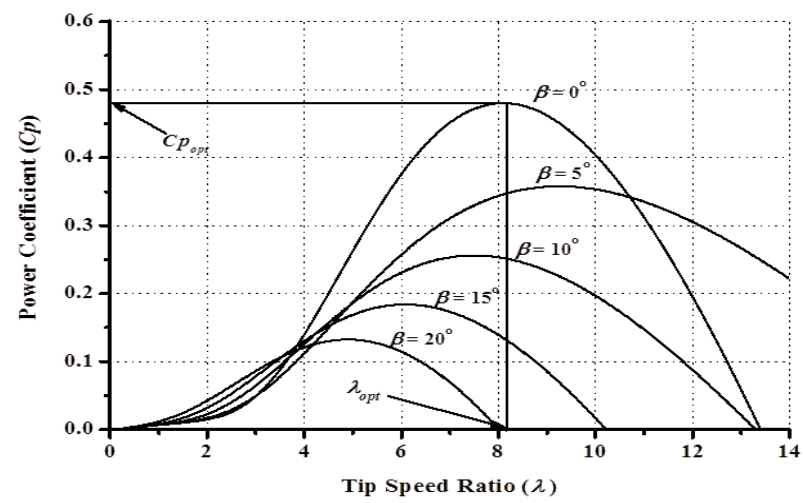

Fig. 2. $\mathrm{Cp}-\lambda$ characteristic for different pitch angle

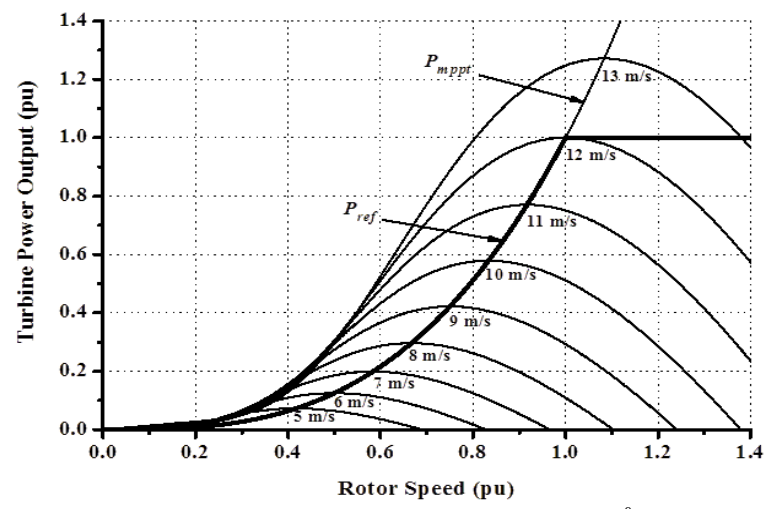

Fig. 3. Turbine power characteristic $\left(\beta=0^{0}\right)$

In modulation technique, Third Harmonic Injection Pulse Wave Modulation (THIPWM) is used in this work. Injection of third harmonic in the reference voltage makes it possible to utilize the voltage reference without over modulation. In addition, the THIPWM can maximize fundamental component of the output voltage [8].

\section{A. Wind Turbine Model}

The mechanical power output of wind turbine captured from the wind power can be calculated as follows [9]:

$$
P_{w}=0.5 \rho \pi R^{2} V_{w}^{3} C_{p}(\lambda, \beta)
$$

where $P_{w}$ is the captured wind power (W), $\rho$ is the air density $\left(\mathrm{Kg} / \mathrm{m}^{3}\right), R$ is the radius of rotor blade $(\mathrm{m}), V_{w}$ is wind speed $(\mathrm{m} / \mathrm{s})$, and $C_{p}$ is the power coefficient. The value of $C_{p}$ is dependent on tip speed ratio $(\lambda)$ and blade pitch angle $(\beta)$ based on the turbine characteristics as follows [9]:

$$
C_{p}(\lambda, \beta)=c_{1}\left(\frac{C_{2}}{\lambda_{i}}-c_{3} \beta-c_{4}\right) e^{\frac{-c_{5}}{\lambda_{i}}}+c_{6} \lambda
$$

with

$$
\frac{1}{\lambda_{i}}=\frac{1}{\lambda-0.08 \beta}-\frac{0.035}{\beta^{3}+1}
$$

where $c_{1}$ to $c_{6}$ denote characteristic coefficients of wind turbine $\left(c_{1}=0.5176, \quad c_{2}=116, \quad c_{3}=0.4, \quad c_{4}=5, \quad c_{5}=21\right.$ and $\left.c_{6}=0.0068\right)$.

The $C p-\lambda$ performance characteristics for different values of $\beta$ are shown in Fig. 2. It is seen that the optimum value of $C_{p}\left(C_{\text {popt }}=0.48\right)$ is achieved at $\lambda=8.1$ with $\beta=0^{0}$. This value of $\lambda$ is set as the optimal value $\left(\lambda_{\text {opt }}\right)$. Fig. 3 depicts the characteristic between the turbine power output and the rotor speed for different wind speeds where the blade pitch angle is set at $0 \mathrm{deg}$. The maximum power output ( $1 \mathrm{pu})$ of wind turbine is obtained at $12 \mathrm{~m} / \mathrm{sec}$ of wind speed and $1 \mathrm{pu}$ of rotational speed.

In variable speed wind turbine system, the rotor speed of wind turbine $\left(\omega_{r}\right)$ is measured in order to determine the Maximum Power Point Tracking (MPPT). In general, it is dificult to measure the wind speed accurately, and hence the maximum power $\left(P_{m p p t}\right)$ should be calculated without measuring the wind speed as expressed in (4) [10]. The reference power $\left(P_{r e f}\right)$ is limited within the rated power of generator.

$$
P_{m p p t}=0.5 \rho \pi R^{2}\left(\frac{\omega_{r} R}{\lambda_{o p t}}\right)^{3} C p_{o p t}
$$

\section{B. Dynamic Model of PMSG}

The dynamic model of PMSG in the d-q rotating reference frame is expressed by the following (5) and (6) [11].

$$
\begin{aligned}
& \frac{d \psi_{s d}}{d t}=-V_{s d}-R_{s} I_{s d}-\omega_{e} \psi_{s q} \\
& \frac{d \psi_{s q}}{d t}=-V_{s q}-R_{s} I_{s q}+\omega_{e} \psi_{s d}
\end{aligned}
$$

with

$$
\begin{aligned}
& \psi_{s d}=L_{s d} I_{s d}+\psi_{m} \\
& \psi_{s q}=L_{s q} I_{s q}
\end{aligned}
$$

where $V_{s d}$ and $V_{s q}$ are stator voltages, $R_{s}$ is the stator winding resistance, $I_{s d}$ and $I_{s q}$ are stator currents, $\omega_{e}$ is the generator rotational speed, $\psi_{s d}$ and $\psi_{s q}$ are the stator flux linkages, $L_{s d}$ and $L_{s q}$ are inductances of the stator winding, and $\psi_{m}$ is the permanent magnet flux linkage. By substituting (7) and (8) into (5) and (6), the deferential equations of PMSG can be obtained as follows:

$$
L_{s d} \frac{d I_{s d}}{d t}=-V_{s d}-R_{s} I_{s d}-\omega_{e} L_{s q} I_{s q}
$$




$$
L_{s q} \frac{d I_{s q}}{d t}=-V_{s q}-R_{s} I_{s q}+\omega_{e} L_{s d} I_{s d}+\omega_{e} \psi_{m}
$$

\section{Mathematical model of LCL Filter}

As previously mentioned, utilization of the LCL filter can lead to stability problem due to resonance. To avoid the resonance a passive damping resistance should be allocated in series with a filter capacitor in the filter. However, adopting a damping resistance can cause power losses and then decrease the filter efficiency. Therefore, in designing the voltage source converter controller system, a passive damping resistance should be taken into account in the plant system model.

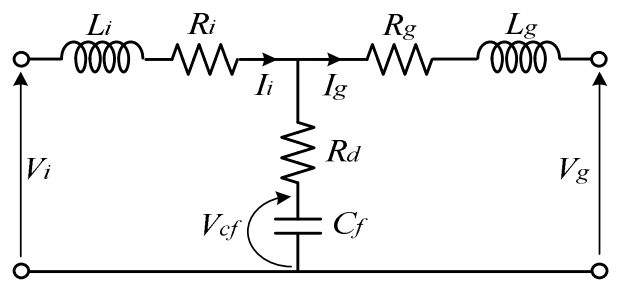

Fig. 4. Single phase LC filter equivalent circuit

Single phase LCL filter equivalent circuit is shown in Fig. 4. The LCL filter is composed of an inverter side inductance $\left(L_{i}\right)$ and its parasitic resistance $\left(R_{i}\right)$, a grid side inductance $\left(L_{g}\right)$ and its parasitic resistance $\left(R_{g}\right)$, a filter capacitor $\left(C_{f}\right)$, and a damping resistance $\left(R_{d}\right) . V_{i}$ and $I_{i}$ are voltage and current on the converter side of the LCL filter. $V_{g}$ and $I_{g}$ are voltage and current on the grid side of the LCL filter. It should be noted that $V_{c f}$ is a voltage on the filter capacitor $\left(C_{f}\right)$. The differential equation of LCL filter in stationary reference frame can be written as follows:

$$
\begin{aligned}
& L_{i} \frac{d I_{i}}{d t}=V_{i}-V_{c f}-\left(R_{i}+R_{d}\right) I_{i}+R_{d} I_{g} \\
& L_{g} \frac{d I_{g}}{d t}=V_{c f}-V_{g}-\left(R_{g}+R_{d}\right) I_{g}+R_{d} I_{i} \\
& C_{f} \frac{d V_{c f}}{d t}=I_{i}-I_{g}
\end{aligned}
$$

From (11) to (13) deferential equations in the d-q rotating reference frame are obtained:

$$
\begin{aligned}
& L_{i} \frac{d I_{i d}}{d t}=V_{i d}-V_{c f d}-\left(R_{i}+R_{d}\right) I_{i d}+L_{i} \omega I_{i q}+R_{d} I_{g d} \\
& L_{i} \frac{d I_{i q}}{d t}=V_{i q}-V_{c f q}-\left(R_{i}+R_{d}\right) I_{i q}-L_{i} \omega I_{i d}+R_{d} I_{g q} \\
& L_{g} \frac{d I_{g d}}{d t}=V_{c f d}-V_{g d}-\left(R_{g}+R_{d}\right) I_{g d}+L_{i} \omega I_{g q}+R_{d} I_{i d} \\
& L_{g} \frac{d I_{g q}}{d t}=V_{c f q}-V_{g q}-\left(R_{g}+R_{d}\right) I_{g q}-L_{i} \omega I_{g d}+R_{d} I_{i q} \\
& C_{f} \frac{d V_{c f d}}{d t}=I_{i d}-I_{g d}+\omega C_{f} V_{c f q} \\
& C_{f} \frac{d V_{c f q}}{d t}=I_{i q}-I_{g q}-\omega C_{f} V_{c f d}
\end{aligned}
$$

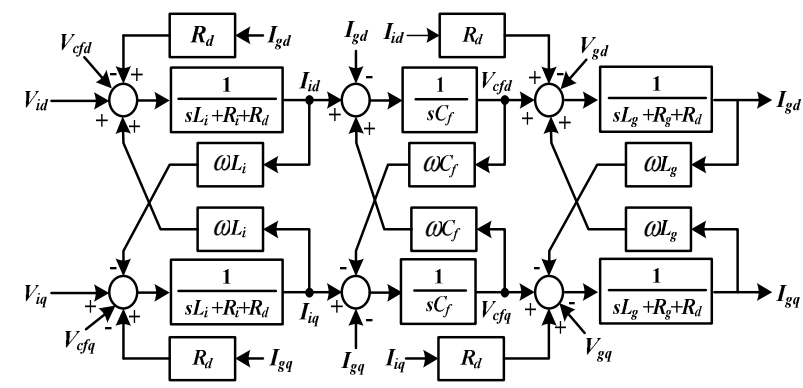

Fig. 6. Block diagram of LC filter in the d-q rotating reference frame

The dynamic block diagram of the grid connected LC filter in the $d-q$ rotating reference frame can be derived as shown in Fig. 6, where s denotes a Laplace operator.

\section{VSWT-PMSG CONTROLLER SYSTEM}

\section{A. Stator side Controller}

Detail of the stator side controller system is presented in a block diagram shown in Fig. 7. The aim of the stator side controller is to control active and reactive power output of the PMSG. The current control loop is designed based on the $\mathrm{d}-\mathrm{q}$ rotating reference frame. The rotor angle position $\left(\theta_{r}\right)$ used in the transformation between $a b c$ and $d q$ variables is obtained from the rotor speed of generator. The active power $\left(P_{s}\right)$ and reactive power $\left(Q_{s}\right)$ of the generator are controlled by the d-axis current $\left(I_{s d}\right)$ and the q-axis current $\left(I_{s q}\right)$, respectively. The value of active power reference $\left(P_{\text {ref }}\right)$ is determined by MPPT method of the wind turbine characteristic as shown in Fig. 3. The reactive power reference $\left(Q_{s}^{*}\right)$ is set to zero for unity power factor operation. The cross couplings $I_{s d} \omega_{e} L_{s d}$ and $I_{s q} \omega_{e} L_{s q}$ should be compensated at the output of the current controllers in order to improve tracking capability. To design controller parameters, the plant transfer function is represented as $1 /\left(R_{s}\right.$ $+L_{s} s$ ) for $\mathrm{d}$ or q current loop. By using the pole placement method, the gain of the PI controller can be tuned.

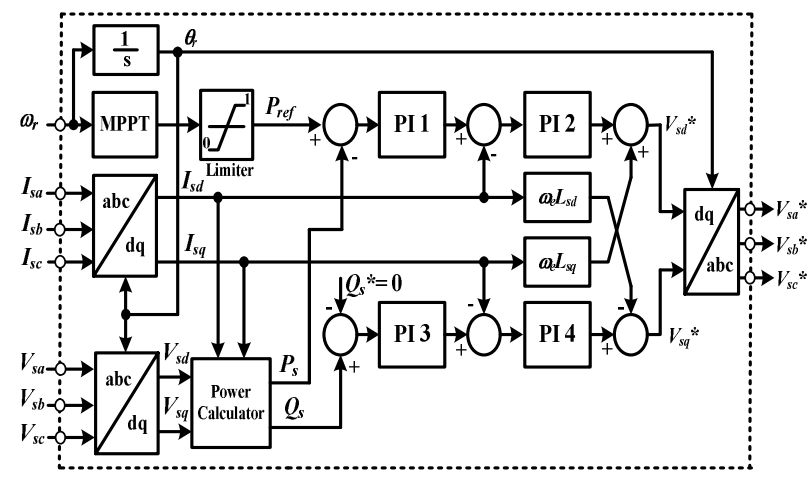

Fig. 7. Stator side controller system

\section{B. Grid side Controller}

Grid side Controller is essential in design of control system because it can dominate the performance of VSWTPMSG connected to a grid system. The aims of VSC control are: 1) to maintain DC link circuit voltage; 2) to control the reactive power exchange with the grid system as well as maintain the power factor to be unity [12]. 


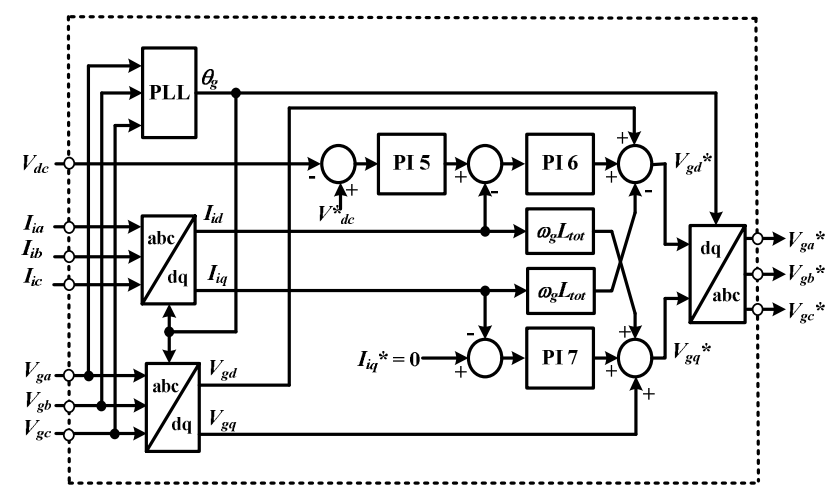

Fig. 8. Grid side controller system

Fig. 8 shows a block diagram of the grid side control system. In this control strategy, the control system based on the $\mathrm{d}-\mathrm{q}$ rotating reference frame, which has same rotational speed as the grid voltage, is implemented. By using the Phase Locked Loop (PLL) the grid side phase angle $(\theta)$ for the $\mathrm{d}-\mathrm{q}$ transformation is obtained. In this paper PLL block introduced in [13] is used. When grid voltages on the stationary reference frame are transformed into the $\mathrm{d}-\mathrm{q}$ rotating reference frame, $V_{g d}$ becomes constant and $V_{g q}$ becomes zero. Therefore, the active and reactive power delivered to the grid can be controlled separately by the daxis current $\left(I_{i d}\right)$ and the q-axis current $\left(I_{i q}\right)$, respectively. In order to assure the active power exchange between PMSG and the grid, the voltage of DC-link capacitor $\left(V_{d c}\right)$ is maintained constant. Hence, the d-axis current reference signal $\left(I_{i d}{ }^{*}\right)$ is determined from output of the DC-voltage controller. For unity power factor operation, the q-axis current reference signal $\left(I_{i q}{ }^{*}\right)$ is also set to zero. To improve tracking capability of control system, the cross coupling terms could be canceled by adding $\omega L_{t o t}$ at the output of the current controllers, where $L_{\text {tot }}$ is total series inductances of the filter and transformer. The output of current controller $\left(V_{g d} *\right.$ and $\left.V_{g q}{ }^{*}\right)$ is transformed into the stationery reference frame $\left(V_{g a} *, V_{g b} *, V_{g c} *\right)$ which is used as reference signal for pulse wave modulation.

\section{Pitch Angle Controller}

Wind turbine power depends on the wind speed, and thus, the output power of a wind generator always fluctuates due to the wind speed variations. In order to maintain the output power of generator under the rated level, a pitch controller is considered as shown in Fig. 9. The transfer function of the pitch actuator is represented by a first-order transfer function with an actuator time constant of $5 \mathrm{~s}$ and the pitch rate limiter of $15 \mathrm{deg} / \mathrm{s}$. A classical PI controller is used to manage tracking error. In VSWT the pitch controller is used to regulate rotational speed of PMSG under its rated value (1pu).

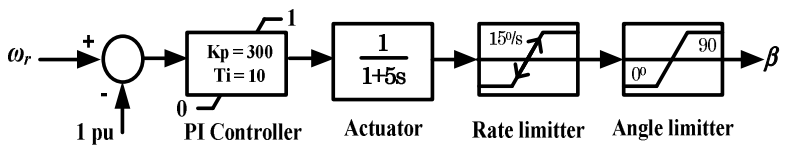

Fig. 9. Pitch angle controller

In this paper 2.5 MVA VSWT-PMSG is considered. Table 1 presents system parameters of the grid connected VSWT-PMSG.
TABLE I

THE SYSTEM PARAMETERS

\begin{tabular}{|c|c|c|}
\hline Component & Parameter & Value \\
\hline \multirow{6}{*}{ PMSG } & Rating & $2.5 \mathrm{MW}$ \\
\hline & $R s$ & $0.01(\mathrm{pu})$ \\
\hline & Lsd & $1.0(\mathrm{pu})$ \\
\hline & $L s q$ & $0.7(\mathrm{pu})$ \\
\hline & $\psi m$ & $1.4(\mathrm{pu})$ \\
\hline & $\mathrm{H}$ & $3.0(\mathrm{sec})$ \\
\hline \multirow{5}{*}{$\begin{array}{c}\mathrm{AC} / \mathrm{DC} / \mathrm{AC} \text { Power } \\
\text { Converter }\end{array}$} & SSC frequency Switching & $1 \mathrm{kHz}$ \\
\hline & GSC frequency Switching & $4 \mathrm{kHz}$ \\
\hline & Grid Frequency & $50 \mathrm{~Hz}$ \\
\hline & DC Link capacitor & $25000 \mu \mathrm{F}$ \\
\hline & DC Link voltage & $1.75 \mathrm{kV}$ \\
\hline \multirow{4}{*}{ Transformer } & Total winding inductance $(L t)$ & $0.040 \mathrm{pu}$ \\
\hline & Total winding resistance $(R t)$ & $0.016 \mathrm{pu}$ \\
\hline & Converter side voltage & $1.0 \mathrm{kV}$ \\
\hline & Grid side voltage & $6.6 \mathrm{kV}$ \\
\hline
\end{tabular}

\section{GRID SidE CURRENT CONTROL ANALYSIS WITH LCL FILTER CONSIDERED}

\section{A. LCL Filter Parameters}

In order to obtain the LCL filter parameters, the system conditions shown in Table I are considered. There are many methods that may be considered in determining the filter parameters. However, in this paper procedure and limitations of LCL filter parameters presented in [6] are considered.

According to the parameters in Table I, $0.4 \Omega$ base impedance, $1.3 m H$ base inductance, and $8000 \mu F$ base capacitance are calculated. As the inductance on the inverter side $\left(L_{i}\right)$, $5.0 \%$ of base inductance is adopted. In order to calculate the grid side inductance $\left(L_{g}\right)$, the transformer inductance $\left(L_{t}\right)$ should be considered. $4 \%$ of base inductance has been adopted as transformer inductance. Adding a small value of grid side inductance $\left(L_{g}\right)$, total $4.1 \%$ of base inductance is obtained. The initial value for filter capacitor $\left(C_{f}\right)$ is set to maximum limitation (5\%). The resonance frequency of LCL filter is around $1.4 \mathrm{kHz}$.

\section{B. Dynamic Stability Analysis of Current Controller}

In order to analyze the dynamic stability of the control system, the block diagram of LCL filter in the d-q rotating reference frame shown in Fig. 6 is considered as a plant system. In this study, the d-axis and the q-axis components are assumed identical, and hence the plant system can be modeled by using one axis component only. Fig. 10 shows proposed block diagram of the d-axis component, where the cross coupling and grid voltage are neglected. It should be noted that the inductance $\left(L_{t}\right)$ and reactance $\left(R_{t}\right)$ of transformer are included in $L_{g}$ and $R_{g}$.

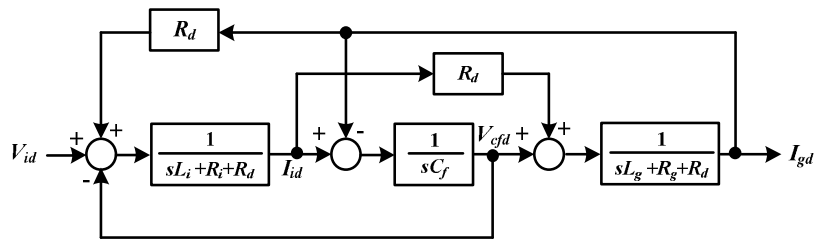

Fig. 10. LCL filter model with d-axis component only

A block diagram of the current control loop is shown in Fig. 11. The controller is composed of a PI controller, a processing delay, and a plant system. Transfer function of the plant system $\left(I_{i d} / V_{i d}\right)$ is simply obtained from Fig. 10. The transfer function has the converter side voltage $\left(V_{i d}\right)$ as input 
and the converter side current $\left(I_{i d}\right)$ as output. There is a time delay $\left(T_{d}\right)$ in the control system for the digital processing. The time delay is composed of one sample delay caused by switching frequency $\left(T_{s}=1 / f_{s}\right)$ and one half sample delay caused by the dead time of PWM converter $\left(T_{c n v}=1 / T_{s}\right)$. For PI controller usually the integral time constant $\left(T_{i}\right)$ is set equal to the plant system time constant $\left(L_{t o t} / R_{t o t}\right)$ [7], where $L_{t o t}$ and $R_{t o t}$ are total of series inductances and its parasitic resistances of the plant system, respectively.

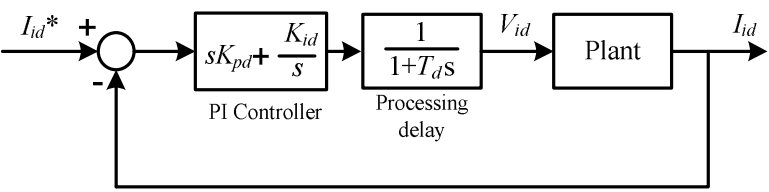

Fig. 11. Block diagram of current control loop

The dynamic stability of the controller system is analyzed based on frequency responses in bode diagram and step response. The initial gain is obtained by using optimum modulus criterion [14]. Fig. 12 shows a bode diagram of the current control loop for four different damping resistances. The bode diagram shows that reducing damping resistance can make system dynamic stability poor. Fig. 13 shows a bode diagram of the current control loop for four different $K_{p d}$ with $R_{d}$ value of $0.09 \mathrm{ohm}$ (around one third of impedance at frequency resonance). It is seen that increasing proportional gain of PI controller leads high frequency response and decreased magnitude of the gain margin. According to Figs. 12 and 13, it is concluded that a good stability performance of the control system can be obtained by selecting a suitable combination between $R_{d}$ and $K_{p d}$. In addition, Fig. 14 shows the step response of current controller for different $K_{p d}$, in which the settling time and overshoot of the step response can be analyzed.

In this study, in order to stabilize the current controller, gain margin $(\mathrm{Gm})$ larger than $6 \mathrm{~dB}$ and phase margin $(\mathrm{Pm})$ larger than $45 \mathrm{deg}$ are required for step response less than or equal $2.5 \mathrm{msec}$ of settling time and 3\% maximum overshoot. With a minimum damping resistance of $R_{d}=0.05 \mathrm{ohm}$ and maximum gain $K_{p d}=0.20$, stable loop with a gain margin of $6.42 \mathrm{~dB}$ and a phase margin of $73.8 \mathrm{deg}$ is obtained as shown in Fig. 15. Step response of the current control loop in discrete system is depicted in Fig. 16. It is seen that the settling time of response is $2.41 \mathrm{msec}$ and maximum overshoot is $2.76 \%$.

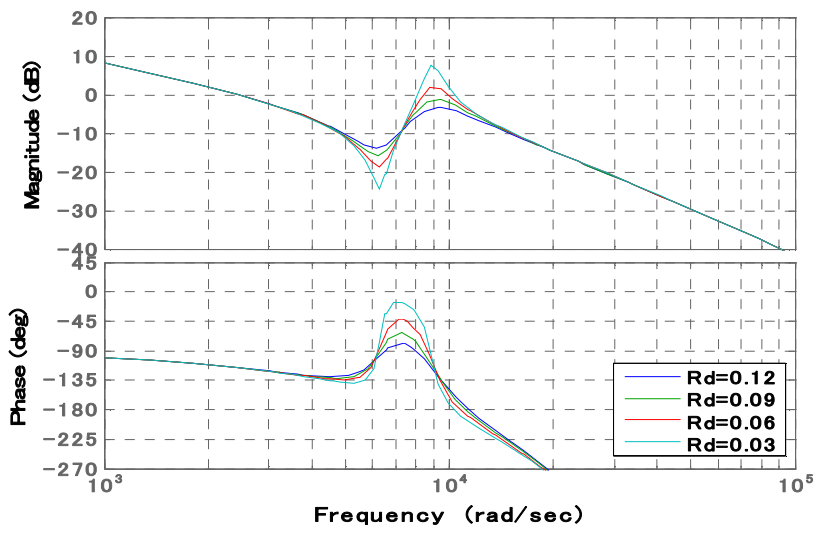

Fig. 12. Bode diagram of current controller for different $R_{d}$

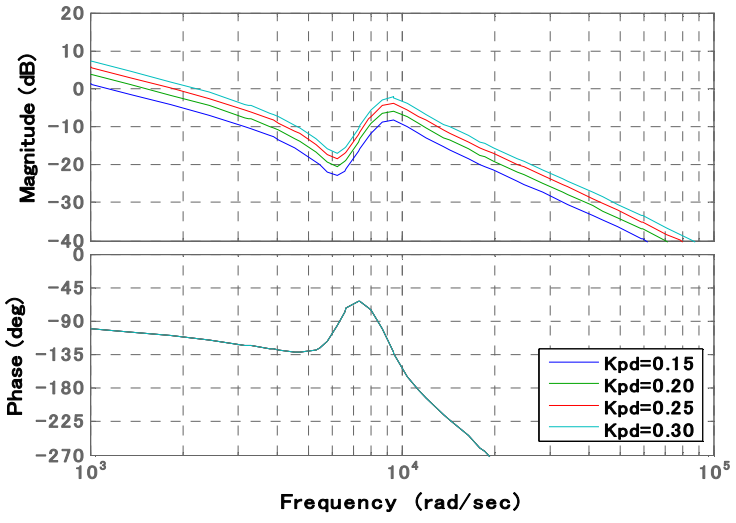

Fig. 13. Bode diagram of current controller for different $K_{p d}$

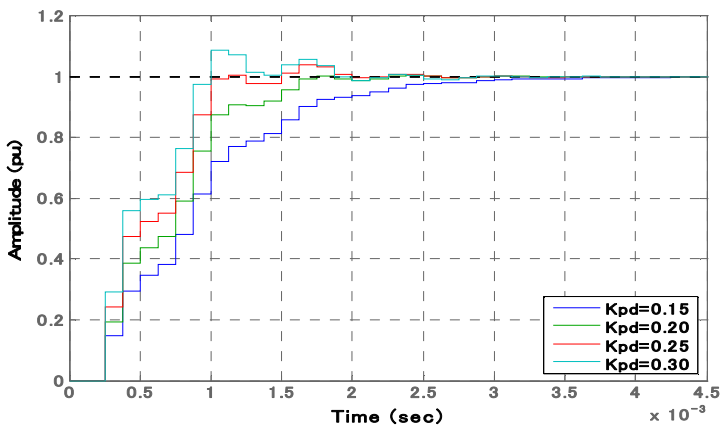

Fig. 14. Step response of current controller for different $K_{p d}$

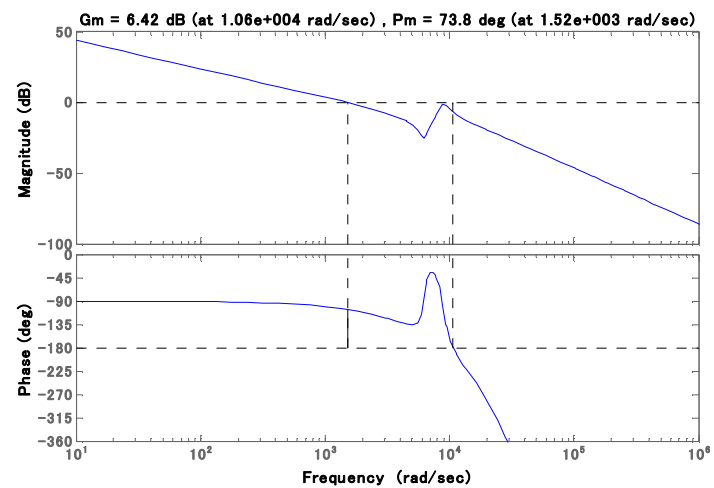

Fig. 15. Bode diagram of current controller $\left(R_{d}=0.05 \mathrm{ohm}, K_{p d}=0.20\right)$.

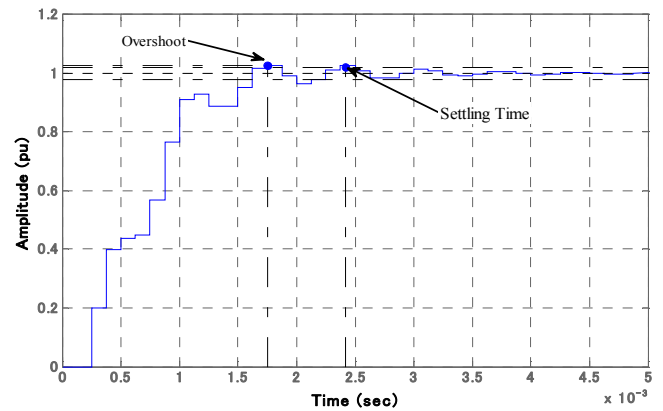

Fig. 16. Closed loop step response of current controller $\left(R_{d}=0.05 \mathrm{ohm}\right.$, $K_{p d}=0.20$ )

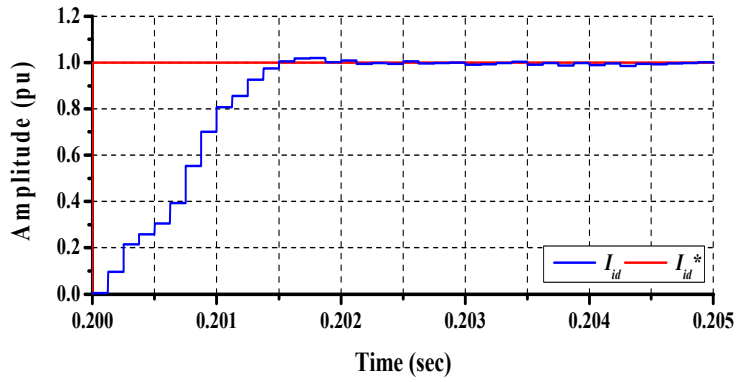

Fig. 17. Step response of d-axis current obtained by Matlab/Simulink 


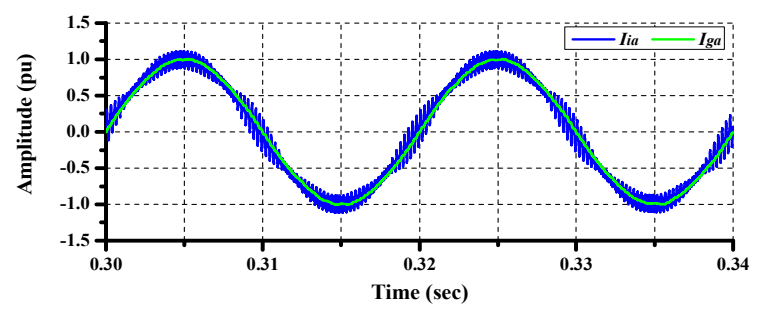

Fig. 18. Current observed on phase A

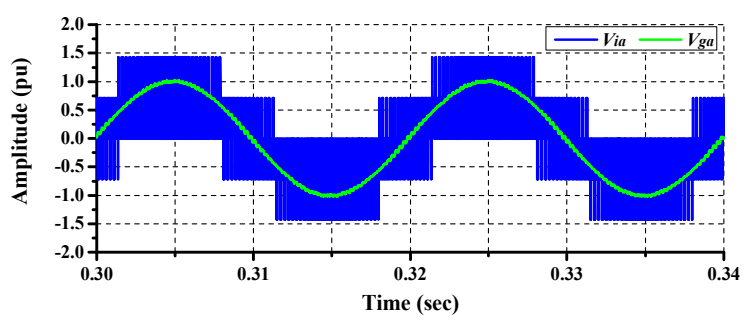

Fig. 19. Voltage observed on phase A

The current controller performance and effectiveness of the LCL filter have been verified by using power system blockset of Matlab/Simulink. Fig 17 shows the step response observed on the $I_{i d}$ of controller system. It is seen that the step response in Fig. 17 has good agreement with analytical response in Fig 16. The current and voltage responses on the converter side and grid side of the LCL filter are shown in Figs. 18 and 19, respectively. It is seen that the filter attenuates the harmonic distortion very effectively. The THD (total harmonic distortion) is measured by using Fast Fourier Transform (FFT) tool in Matlab. The THD of the grid side current is $1.17 \%$, while the THD of the grid side voltage is $2.29 \%$.

\section{SimUlation StUdy}

Validity of the design and analysis method explained above has been evaluated using the model system shown in Fig. 20. A VSWT- PMSG rated at $2.5 \mathrm{MW}$ is connected to $6.6 \mathrm{kV}$ distribution system through converters composed of stator side and grid side VSCs, a LCL filter, a 1.0/6.6 kV step up transformer, and a double circuit transmission line. A local load rated at $1 \mathrm{MW}$ is installed near the wind generator. In the figure, impedances of the transmission line are shown in the form of $\mathrm{R}+\mathrm{j} X$, where $\mathrm{R}$ and $\mathrm{X}$ represent the resistance and reactance, respectively. System base power is 100 MVA.

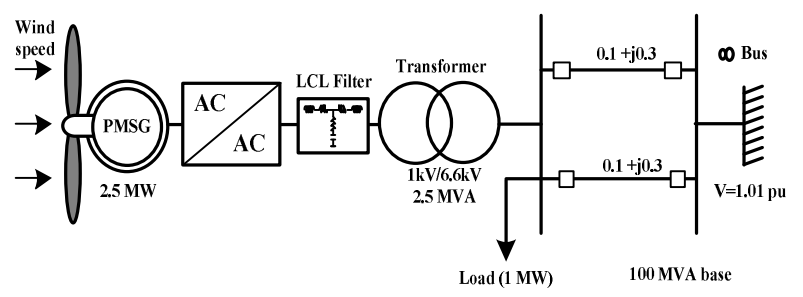

Fig. 20. Model system

In order to evaluate the dynamic performances of the proposed system, the wind speed data shown in Fig. 21 is considered. Simulations were performed by using PSCAD/EMTDC. Fig. 22 depicts the pitch angle response of the VSWT-PMSG, which is activated when the wind speed exceeds the rated value. The active power reference $\left(P_{\text {ref }}\right)$, the active power output of PMSG $(P S)$, and the active power delivered to the grid $\left(P_{g}\right)$ are shown in Fig. 23. It is seen that $P_{S}$ and $P_{g}$ follow $P_{r e f}$ very well. The reactive power outputs of the generator and the grid side converter are kept almost

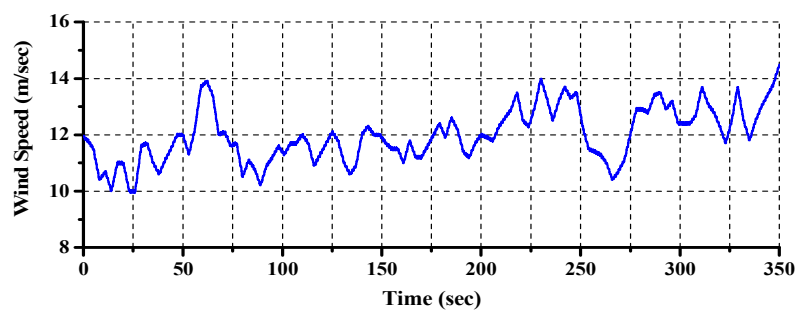

Fig. 21. Wind speed data

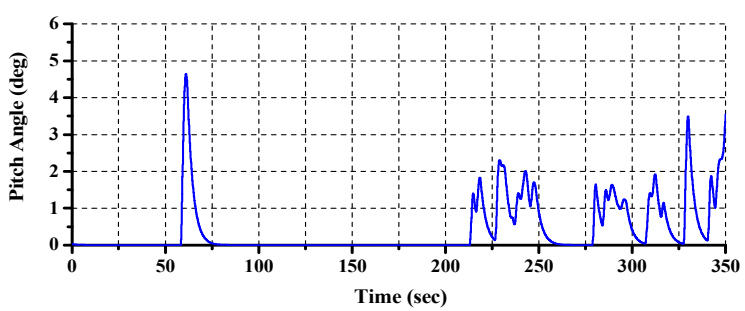

Fig. 22. Pitch angle response

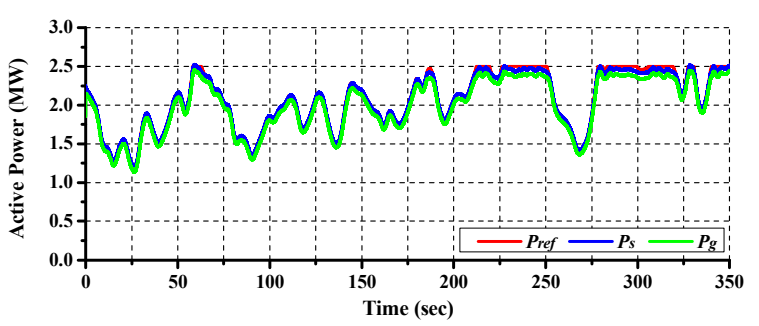

Fig. 23. Active power output

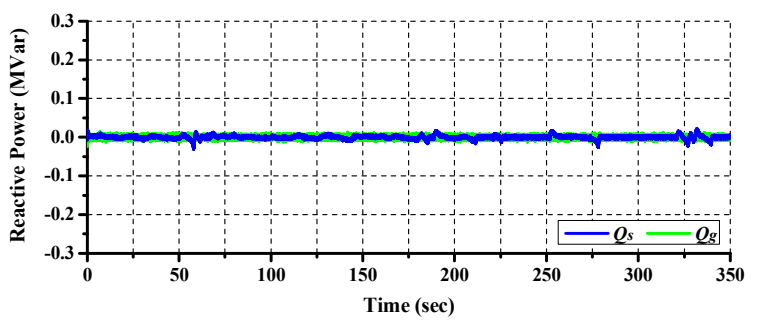

Fig. 24. Reactive power output

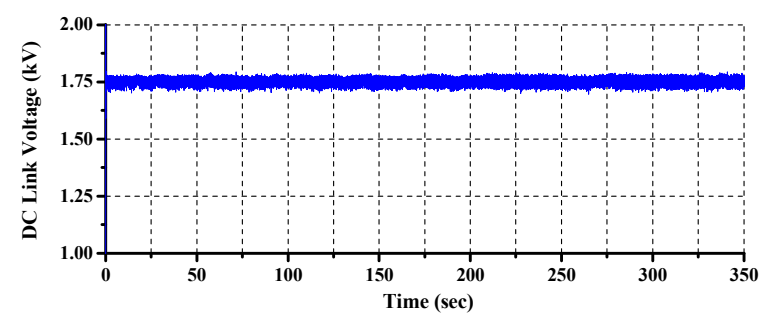

Fig. 25. DC link voltage

zero as shown in Fig 24. The response of the DC link voltage is shown in Fig. 25. It is seen that the DC voltage can also be maintained constant at rated value $(1.75 \mathrm{kV})$.

\section{CONCLUSION}

In this paper, design and analysis of the control system for 2.5 MW class of VSWT-PMSG connected to a distribution grid system through LCL filter is presented. Design and analysis of the grid side current controlled voltage source converter is focused, in which passive damping resistance of the filter and gains of PI controllers of VSC are selected based on frequency response of the bode diagram and dynamic step response. According to the simulation results it is concluded that the controller system is effective to control active and reactive power delivered to the grid. Moreover, the LCL filter is very effective to attenuate the harmonic distortions. 


\section{ACKNOWLEDGEMENT}

This study was supported by a Grant-in-Aid for scientific Research (B) from The Ministry of Education, Science, Sports and Culture of Japan.

\section{APPENDIX}

Table II shows PI controller parameters used in the simulation analyses. The parameters for PI 1 to PI 4 (PI controllers for the stator side controller) are selected by using the pole placement method. The parameters for DC link voltage controller of the grid side controller (PI 5) can be selected same as those of PI 6 and PI 7.

TABLE II

PI CONTROLLER GAINS

\begin{tabular}{|c|c|c|}
\hline PI Controller & $K_{p}$ & $T_{i}$ \\
\hline PI 1 & 0.1 & 0.02 \\
\hline PI 2 & 0.4 & 0.05 \\
\hline PI 3 & 0.1 & 0.02 \\
\hline PI 4 & 0.4 & 0.0497 \\
\hline PI 5 & 0.2 & 0.0497 \\
\hline PI 6 & 0.2 & 0.0497 \\
\hline PI 7 & 0.2 & 0.0497 \\
\hline
\end{tabular}

\section{REFERENCES}

[1] T. Ackermann, G. Andersson, L. So"der, "Distributed generation: a definition," Elsevier, Electric Power Systems Research, Vol. 57, pp. 195-204, 2001

[2] Thomas Ackermann, Wind power in power system, UK: John Wiley \& Sons, 2005, pp. 53-65.

[3] Y. Shankir, "Review of wind turbines' drive systems and why Gearless direct drive," RCREEE Wind Energy Building Capacity Program-Stage 2 Rabat, Tangier 29 March - 2nd Apr. 2010.

[4] P. Vas, Electrical machines and Drive $S-A$ space vector theory approach, New York: Oxford Univ. Press 1992.

[5] W. A. Hill and S. C. Kapoor, "Effect of two-level PWMsources on plant power system harmonics," in Conf. Rec. IEEE-IAS Annu. Meeting, pp. 1300-1306, 1998,

[6] M. Liserre, Frede Blaabjerg, Steffan Hansen, "Design and Control of an LCL-filter based Three-phase Active Rectifier," IEEE Trans, Industry Applications Conference, Vol. 41, No. 5, pp. 1281 - 1291, Sept/Oct. 2005.

[7] V. Blasko and V. Kaura, "A novel control to actively damp resonance in input lc filter of a three-phase voltage source converter," IEEE Trans.Ind. Appl., vol. 33, no. 2, pp. 542-550, Mar./Apr. 1997.

[8] B. Farid O. Amar, "A Study of New Techniques of Controlled PWM Inverters, " European Journal of Scientific Research, Vol.32 No.1. pp. 77-87, 2009

[9] Siegfried Heier, Grid integration of wind energy conversion systems, John Wiley \& Sons Ltd 1998, pp. 34-36
[10] S.M.Muyeen, Ahmed Al-Durra, J. Tamura, "Variable Speed Wind Turbine Generator System with Current Controlled Voltage Source Inverter", Energy Conversion and Management, Vol. 52, No. 7, pp. 2688-2694, Jul. 2011.

[11] Shuhui Li, Timothi A. Haskew, and Ling Xu "Conventional and novel control design for direct drivrn PMSG wind turbines," Elsevier, Electric Power System research, Vol. 80, pp. 328-338, 2010.

[12] L. M. Fernandes, C. A. Garcia, F. Jurado, "Operating Capability as a PQ/PV node of a Direct-Drive Wind Turbine based on a permanent magnet synchronous generator, " Elsevier, Renewable Energy, Vol. 35, pp. 1308-1318, 2010.

[13] S.M.Muyeen, R. Takahashi, T.Murata, J. Tamura, "A Variable Speed Wind Turbine Control Strategy to Meet Wind Farm Grid Code Requirements, "IEEE Trans, Power Systems, Vol .25, No. 1, pp. 331340, Feb. 2010.

[14] Cvejn, J, "PI/PID Controller Design for FOPDT Plants Based on the Modulus Optimum Criterion," In Proceedings of the 18th International Conference on Process Control, Tatranská Lomnica, Slovakia, June $14-17$, pp. 301-306, Jun, 2011.

\section{BIOGRAPHIES}

Marwan Rosyadi received Sarjana Teknik (equivalent to B.Sc. degree) from Adhi Tama Institute of Technology Surabaya and M. Eng. degree from Sepuluh Nopember Institute of Technology, Indonesia, in 2004 and 2006 respectively, all in Electrical Engineering. Presently he is working towards his Ph.D Degree at the Kitami Institute of Technology, Kitami, Hokkaido, Japan. His research interests are stability and control of power system including wind generator.

S. M. Muyeen received his B.Sc. Eng. Degree from Rajshahi University of Engineering and Technology (RUET), Bangladesh, formerly known as Rajshahi Institute of Technology, in 2000, and M. Sc. Eng. and Dr. Eng. Degrees from Kitami Institute of Technology, Japan, in 2005 and 2008 respectively, all in Electrical and Electronic Engineering. After completing his Ph.D. program he worked as a Postdoctoral Research Fellow under the versatile banner of Japan Society for the Promotion of Science (JSPS) from 2008-2010 at the Kitami Institute of Technology, Japan. Presently he is working as Assistant Professor in Electrical Engineering department at the Petroleum Institute, in UAE. His research interests are power system stability and control, electrical machine, FACTS, energy storage system (ESS), Renewable Energy, and HVDC system.

Rion Takahashi received his B.Sc. Eng. and Dr. Eng. Degrees from Kitami Institute of Technology, Japan, in 1998 and 2006 respectively, all in Electrical and Electronic Engineering. Now he is working as Associate Professor in Department of Electrical and Electronic Engineering, Kitami Institute of Technology. His major research interests include analysis of power system transient, FACTS and wind energy conversion system.

Junji Tamura received his B. Sc. Eng. Degree from Muroran Institute of Technology, Japan, in 1979 and M.Sc. Eng. and Dr. Eng. degrees from Hokkaido University, Japan, in 1981 and 1984 respectively, all in electrical engineering. He became a lecturer in 1984, an Associate Professor in 1986, and a Professor in 1996 at the Kitami Institute of Technology, Japan. Currently he is a Vice President of the Kitami Institute of Technology. Dr. Tamura is a Senior Member of the IEEE Power Engineering Society. 